\title{
Retroviral-mediated Transfer of the Human Glucocerebrosidase Gene into Cultured Gaucher Bone Marrow
}

Jan A. Nolta, Xiao Jin Yu, Ingrid Bahner, and Donald B. Kohn

Division of Research Immunology/Bone Marrow Transplantation, Children's Hospital of Los Angeles, Departments of Pediatrics and Microbiology, University of Southern California School of Medicine, Los Angeles, California 90027

\begin{abstract}
Gaucher disease, a lysosomal glycolipid storage disorder, results from the genetic deficiency of an acidic glucosidase, glucocerebrosidase (GC). The beneficial effects of allogeneic bone marrow transplantation (BMT) for Gaucher disease suggest that GC gene transduction and the transplantation of autologous hematopoietic stem cells (gene therapy) may similarly alleviate symptoms. We have constructed a retroviral vector, L-GC, produced by a clone of the amphotropic packaging cell line PA317, which transduces the normal human GC cDNA with high efficiency. Whole-marrow mononuclear cells and CD34-enriched cells from a 4-yr-old female with type 3 Gaucher disease were transduced by the L-GC vector and studied in long-term bone marrow culture (LTBMC). Prestimulation of marrow with IL-3 and IL-6, followed by co-cultivation with vector-producing fibroblasts, produced gene transfer into 40-45\% of the hematopoietic progenitor cells. The levels of GC expression in progeny cells (primarily mature myelomonocytic) produced by the LTBMC were quantitatively analyzed by Northern blot, Western blot, and glucocerebrosidase enzyme assay. Normal levels of GC RNA, immunoreactive protein, and enzymatic activity were detected throughout the duration of culture. These studies demonstrate that retroviral vectors can efficiently transfer the GC gene into long-lived hematopoietic progenitor cells from the bone marrow of patients with Gaucher disease and express physiologically relevant levels of GC enzyme activity. (J. Clin. Invest. 1992. 90:342-348.) Key words: Gaucher disease $\bullet$ gene therapy $\bullet$ longterm bone marrow culture $\bullet$ long-term culture-initiating cells
\end{abstract}

\section{Introduction}

Gaucher disease is the most common human lysosomal storage disorder. It is caused by mutations in the structural gene for the enzyme glucocerebrosidase (GC) ${ }^{1}$ (EC 3.2.1.45; reviewed in references 1 and 2). Decreased GC activity leads to the accu-

Address reprint requests to Dr. Kohn, Division of Research Immunology/Bone Marrow Transplantation, Children's Hospital of Los Angeles, 4650 Sunset Boulevard, Mailstop No. 62, Los Angeles, CA 90027.

Received for publication 24 January 1992 and in revised form 18 March 1992.

1. Abbreviations used in this paper: BMT, bone marrow transplantation; GC, glucocerebrosidase; IMDM, Iscove's modified Dulbecco's medium; LTBMC, long-term bone marrow culture; LTCIC, long-term culture initiating cells; LTR, long terminal repeat; VPF, vector-producing fibroblast.

J. Clin. Invest.

(C) The American Society for Clinical Investigation, Inc.

0021-9738/92/08/0342/07 \$2.00

Volume 90, August 1992, 342-348 mulation of the substrate glycolipid in macrophages throughout the reticuloendothelial system. Extensive glycolipid storage results in the symptoms of hepatosplenomegaly, hypersplenism, and lytic bone lesions. There are three clinically distinct forms of Gaucher disease: nonneuronopathic (type 1), acute neuronopathic (type 2), and subacute neuronopathic (type 3 ).

Allogenic bone marrow transplantation (BMT) results in the replacement of the reticuloendothelial system with donorderived macrophages produced from engrafted hematopoietic stem cells. BMT has been shown to have a beneficial effect on the somatic symptoms of patients with types 1 and 3 Gaucher disease, although the long-term effects on neurologic and intellectual function remain to be determined (3-5). Currently, only allogeneic transplants from fully histocompatible donors are deemed appropriate treatment for Gaucher disease, owing to the higher risks of graft rejection or graft-versus-host disease with less well-matched donors (6).

Current progress in gene transduction techniques and the cloning of the normal human $\operatorname{GC} \operatorname{cDNA}(7,8)$ allows consideration of gene therapy for Gaucher disease (reviewed in references 9 and 10). The insertion of a normal GC gene into a Gaucher patient's bone marrow stem cells followed by an autologous BMT (gene therapy) could potentially restore macrophage GC activity without the risk of immunologic complications from an allogeneic transplant. Retroviral-mediated transfer of the human GC cDNA has been shown to produce physiological levels of GC in murine bone marrow (11-13), Gaucher fibroblasts $(14,15)$, and Gaucher bone marrow cells (16).

In the present study we report construction of a high-titer, helper-free retroviral vector, L-GC, which contains the human GC cDNA under control of the Moloney murine leukemia virus long-terminal repeat (LTR). Using a protocol that we had previously developed to produce highly efficient gene transfer into normal human marrow (17), we have successfully transduced Gaucher marrow with the L-GC vector. The transduced marrow was maintained in long-term bone marrow culture (LTBMC) for 5 mo. Vector-derived GC expression was measured after various periods of culture. The mature myelomonocytic cells which were produced in the nonadherent cell fraction of the LTBMC had levels of vector-derived GC mRNA, immunoreactive protein, and enzymatic activity in the range of normal myelomonocytic cells. These results demonstrate the ability of retroviral-mediated GC gene transfer into hematopoietic progenitor cells to correct the genetic defect of Gaucher disease in the specific cells involved in the pathogenesis.

\section{Methods}

Retroviral vectors and vector-producing fibroblasts (VPF). The LN vector was provided as a high-titer VPF PA317 packaging clone by Dr. 
A. D. Miller, Seattle, WA $(18,19)$. L-GC was constructed by placing a normal human GC cDNA between the 5' LTR-leader (Psi) region fragment (EcoR1-EcoR1) and 3' LTR and pBR322 fragment (Cla 1/ EcoR1) of pLNCX $(18,20)$. The L-GC vector plasmid was co-transfected with pSV2Neo into the Psi2 ecotropic packaging cell line (21), then cross-transduced into PA317 amphotropic packaging cells (American Type Culture Collection, Rockville, MD). PA317 clones were obtained as described (13). PA317 cells were maintained in DME high glucose (Irvine Scientific, Santa Ana, CA) with 10\% FCS. A PA317 VPF clone (PA317/L-GC 6 ), which transduced maximal levels of enzymatically active human GC into 3T3 cells, was selected for further study. Absence of infectious helper virus was verified by the lack of amphotropic env sequences detectable by polymerase chain reaction (PCR) of the transduced 3T3 cells (22).

Source of human marrow. Marrow was obtained from a 4-yr-old female with type 3 Gaucher disease as backup marrow harvest before a matched, unrelated donor bone marrow transplant. The patient had presented at $1 \mathrm{yr}$ of age with massive splenomegaly. She underwent a splenectomy at 2 yr of age, owing to secondary respiratory compromise. At the time of marrow collection, she had massive hepatomegaly and oculomotor apraxia. On biopsy, her bone marrow was $50 \%$ replaced by typical Gaucher cells; her liver biopsy showed minimal hepatic fibrosis. She is homozygous for the "neuronopathic" mutation, a cytosine residue substituted for a thymidine at nucleotide 1448 (determined by Dr. Ernest Beutler, Scripps Clinic and Research Foundation, La Jolla, CA). Normal human bone marrow was obtained from surplus cells harvested for BMT from normal marrow donors. Use of these samples was approved by the Committee on Clinical Investigations at Children's Hospital of Los Angeles.

Isolation of $\mathrm{CD}_{34^{+}}$progenitor cells. The mononuclear cell fraction was obtained from whole marrow by centrifugation on ficoll-percoll density gradient. The collected cells were washed twice in HBSS / $10 \%$ FCS and live cells were enumerated by trypan blue exclusion. Cells were plated at a concentration of $1 \times 10^{6} / \mathrm{ml}$ in Iscove's modified Dulbecco's medium (IMDM, Irvine Scientific) with $20 \%$ FCS and cultured overnight to remove adherent cells. Nonadherent marrow was collected, washed twice in cold $1 \times$ PBS, counted, and diluted to a concentration of $1 \times 10^{7}$ cells per ml PBS. Cells were incubated with the anti-CD34 monoclonal antibody My10 (provided by Dr. Curt Civin, Johns Hopkins Medical Center) at a concentration of $5 \mu \mathrm{g} / \mathrm{ml}$ of cell suspension at $4^{\circ} \mathrm{C}$ for $1 \mathrm{~h}$, with gentle intermittent mixing. After washing cells twice in PBS / 5\% FCS, goat anti-mouse conjugated magnetic beads (Dynal, Oslo, Norway) were added at a concentration of one bead per two cells. Samples were incubated at $4^{\circ} \mathrm{C}$ for $1 \mathrm{~h}$, with mixing. CD $34^{+}$cells, to which beads had been bound, were isolated with a magnet (23). Between $0.5 \%$ and $1.5 \%$ of mononuclear marrow cells are routinely recovered in the $\mathrm{CD} 34^{+}$population. Counterstaining with the anti-CD34 monoclonal antibody $8 \mathrm{G} 12$ (obtained from Dr. Peter Lansdorp, Vancouver, BC) showed $>95 \%$ of the cells to be CD34 ${ }^{+}$.

Marrow preculture procedure. Marrow cells were stimulated for $2 \mathrm{~d}$ by preculture in medium supplemented with recombinant IL-3 and IL-6. The preculture medium consisted of IMDM with $30 \%$ heat-inactivated FCS, $1 \%$ deionized BSA, $100 \mathrm{U} / \mathrm{ml}$ penicillin, $10 \mu \mathrm{g} / \mathrm{ml}$ streptomycin, $2 \mathrm{mM}$ L-glutamine, $10^{-4} \mathrm{M}$ 2-mercaptoethanol, $10^{-6} \mathrm{M}$ hydrocortisone, $5 \mathrm{ng} / \mathrm{ml}$ recombinant human IL-3, and $50 \mathrm{U} / \mathrm{ml}$ recombinant human IL-6 (Immunex Corp., Seattle, WA). Total marrow mononuclear cell populations were plated at $1 \times 10^{6}$ cells $/ \mathrm{ml}$ in 25 $\mathrm{cm}^{2}$ filter-vent flasks (Costar, Cambridge, MA). CD34 ${ }^{+}$cells were precultured at $1 \times 10^{5}$ cells $/ \mathrm{ml}$ in $3 \mathrm{ml}$ of medium in six-well plates (Costar). Cells were maintained at $37^{\circ} \mathrm{C}, 5 \% \mathrm{CO}_{2}$ for $48 \mathrm{~h}$ before gene transfer.

Retroviral vector infection protocol. After the 48-h preculture period, nonadherent cells were collected by flushing, and pelleted at 1,400 $\mathrm{rpm}$. Cells were resuspended in preculture medium containing IL-3 and IL- 6 and transferred to plates of VPF, which had been irradiated $(45 \mathrm{~Gy})$ and plated the day before in preculture medium. $3 \times 10^{6} \mathrm{VPF}$ were plated per 100-mm tissue culture dish (Corning Glass, Inc., Corn- ing, NY) for co-cultivation of unsorted marrow, and $3 \times 10^{5} \mathrm{VPF}$ were plated per well in the six-well plates for co-cultivation of $\mathrm{CD} 34^{+}$cells. 5 $\times 10^{6}$ unsorted marrow cells were added to each $100-\mathrm{mm}$ dish and 3 $\times 10^{5} \mathrm{CD}^{+} 4^{+}$cells were added to each six-well plate, without changing the medium. After addition of the precultured marrow to the irradiated VPF monolayers, polybrene (Sigma Chemical Co., St. Louis, MO) was added to a final concentration of $4 \mu \mathrm{g} / \mathrm{ml}$.

Co-cultivation was allowed to proceed for $48 \mathrm{~h}$, with the addition of $0.5 \mathrm{vol}$ fresh medium and additional polybrene after $24 \mathrm{~h}$. The concentrations of IL-3 and IL-6 were maintained throughout the period of prestimulation and co-cultivation. After the co-cultivation period, nonadherent marrow cells were obtained by flushing of the VPF monolayer. The cells were plated for several hours in fresh preculture media to allow adherence of VPF which had been collected. After the adherence step, nonadherent marrow cells were collected and washed, and viable cell numbers were counted by trypan blue exclusion.

Clonogenic assay for hematopoietic progenitors. Directly after gene transfer, hematopoietic progenitor cells were enumerated using the CFU-granulocyte, erythrocyte, monocyte, megakaryocyte (GEMM) assay as described (17). The rates of transfer of the neo gene were determined by measuring the percentage of colony-forming progenitors which were resistant to G418 (Geneticin; Sigma Chemical Co.). For each sample, four replicate plates were made and G418 $(1 \mathrm{mg} / \mathrm{ml}$ active compound) was added to two of these. $5 \times 10^{4}$ cells per plate were used when assaying unseparated mononuclear cell preparations and between 200 and 1,000 cells were used when assaying CD $34^{+}$cells. These plating densities had been determined empirically to yield $\sim 100$ colonies per plate, which is the upper limit that produces distinct, individual colonies. The numbers of total and G418-resistant progenitor-derived colonies were counted after $14 \mathrm{~d}$. In all experiments, marrow transduced by the L-GC vector, which does not contain the neo gene, was completely inhibited from colony formation by this concentration of $\mathrm{G} 418$.

LTBMC. Human LTBMC were initiated immediately after gene transfer. Transduced CD34 ${ }^{+}$cells were maintained in LTBMC by reseeding onto irradiated ( $20 \mathrm{~Gy}$ ) autologous stroma, to sustain clonogenic progenitors. Stromal cells were maintained in IMDM with $12 \%$ horse serum, $12 \% \mathrm{FCS}, 1 \times 10^{-6} \mathrm{M}$ hydrocortisone, $1 \times 10^{-4} \mathrm{M} 2$-mercaptoethanol, $100 \mathrm{U} / \mathrm{ml}$ penicillin, and $10 \mu \mathrm{g} / \mathrm{ml}$ streptomycin. Primary stromal layers were harvested when confluent by incubation at $37^{\circ} \mathrm{C}$ for $20 \mathrm{~min}$ in $0.15 \%$ collagenase (type 1 , Sigma Chemical Co.). After irradiation, stroma was seeded into $25-\mathrm{cm}^{2}$ filter vent flasks (Costar) in $10 \mathrm{ml}$ of media at a concentration of $1 \times 10^{5}$ cells per ml. The next day, the medium was removed and transduced CD $34^{+}$marrow cells were added to the stroma in $10 \mathrm{ml}$ of long-term culture medium at a concentration of $5 \times 10^{4}$ cells per $\mathrm{ml}$. The medium used for LTBMC was: IMDM with $30 \%$ FCS, $1 \%$ deionized BSA, 5\% phytohemagglutinin-stimulated human lymphocyte conditioned medium, 5\% 5637 $\mathrm{CM}, 10^{-6} \mathrm{M}$ hydrocortisone, $10^{-4} \mathrm{M}$ 2-mercaptoethanol, $100 \mathrm{U} / \mathrm{ml}$ penicillin, $10 \mu \mathrm{g} / \mathrm{ml}$ streptomycin, $2 \mathrm{mM}$ L-glutamine, and $25 \mathrm{ng} / \mathrm{ml}$ recombinant human granulocyte/macrophage colony-stimulating factor (GM-CSF) (17). Long-term cultures were fed at 3-5-d intervals by removing $75 \%$ of the spent medium and nonadherent cells and replacing with an equal volume of fresh medium. Cells collected from each culture during the media changes were used for Northern and Western blot or GC enzyme assay.

Northern blot analysis. Cell pellets collected from LTBMC at the times of media changes $\left(\sim 1 \times 10^{6}\right.$ cells per sample $)$ were washed once in $10 \mathrm{ml} 1 \times$ PBS before nucleic acid extraction. Pellets for RNA were resuspended in $200 \mu$ l of PBS and kept on ice until lysis in $4 \mathrm{M}$ guanidine isothiocyanate solution (24). Extraction of RNA, gel electrophoresis, and nucleic acid transfer were as described (11).

Western blot and enzyme assay. Nonadherent cells for protein analysis were obtained from LTBMC in the manner previously described. Pellets were washed four times in $10 \mathrm{ml}$ of PBS to remove proteins from the serum-rich culture medium. Cells were kept on ice until assayed or stored at $-20^{\circ} \mathrm{C}$. Western blots and enzyme assay for human GC were performed as described (11). 


\section{Results}

Generation and characterization of a PA317 clone producing the $L-G C$ retroviral vector. We constructed a recombinant retroviral vector plasmid, L-GC, containing the normal human GC cDNA between the Moloney murine leukemia virus 5' and $3^{\prime}$ LTR (Fig. 1). Clones of the amphotropic packaging cell line PA317 producing L-GC virus were derived as described (13). A clone, PA317/L-GC 6 , was selected for use in this study because it transduced high levels of immunoreactive human GC protein into target 3T3 cells (data not shown).

To determine the number of copies of the L-GC vector provirus contained in the PA317/L-GC 6 clone, genomic DNA was analyzed by Southern blot. DNA was digested with EcoR1, which cuts once in the provirus and releases fragments of varying length for each integrant, dependent upon the location of the nearest restriction site in the DNA flanking the provirus. The blot was probed with the normal human GC cDNA (Fig. 2 $A)$. The upper band, which is common to both the control cell line PA317/LN and the PA317/L-GC 6 clone, represents the endogenous murine $\mathrm{GC}$ gene, which hybridizes with the human GC probe at low stringency. PA317/L-GC 6 was shown to contain at least six additional hybridizing bands, and hence contains at least six copies of integrated L-GC provirus.

To analyze expression of GC protein in the PA317/L-GC cells, we performed a Western blot analysis of solubilized cell proteins. We used the monoclonal antibody $8 \mathrm{E} 4$, which is specific for human GC (25). The second lane in Fig. $2 B$ shows the pattern of immunoreactive GC in normal human bone marrow, which is a heterogeneous band, owing to glycosylation, most predominant at 58 and $65 \mathrm{kD}$. Lane 3 contains protein from the parental PA317 packaging cell line which does not cross-react with 8E4. Together, lanes 2 and 3 demonstrate the specificity of $8 \mathrm{E} 4$ for human GC. Lane 4 contains an equal amount of protein from the PA317/L-GC 6 clone. It can be seen that this clone produces immunoreactive human GC protein at a level greatly exceeding that found in normal human marrow.

Finally, we quantitated the human GC enzymatic activity produced in the PA317/L-GC 6 clone. Normal human marrow had a total of $211 \mathrm{U}$ of activity, and $>75 \%$ of this was immunoprecipitated by $8 \mathrm{E} 4$ (Fig. $2 \mathrm{C}$ ). As expected, none of the murine $\mathrm{GC}$ in the parental PA317 cell line was precipitated by the

LN

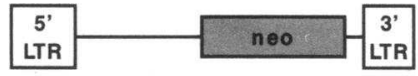

L-GC

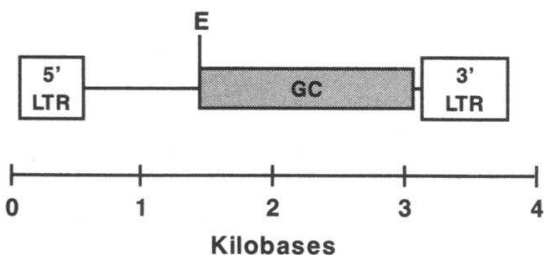

Figure 1. Diagram of the LN and L-GC retroviral vector proviruses. Each contains the 5' and $3^{\prime}$ LTR and 5' leader regions derived from Moloney murine leukemia virus and modified as described (18). The LN vector carries the bacterial neomycin phosphotransferase gene ( neo) and L-GC carries a normal human GC cDNA $(G C)$. The recognition site for the restriction endonuclease EcoR 1 is indicated $(E)$.

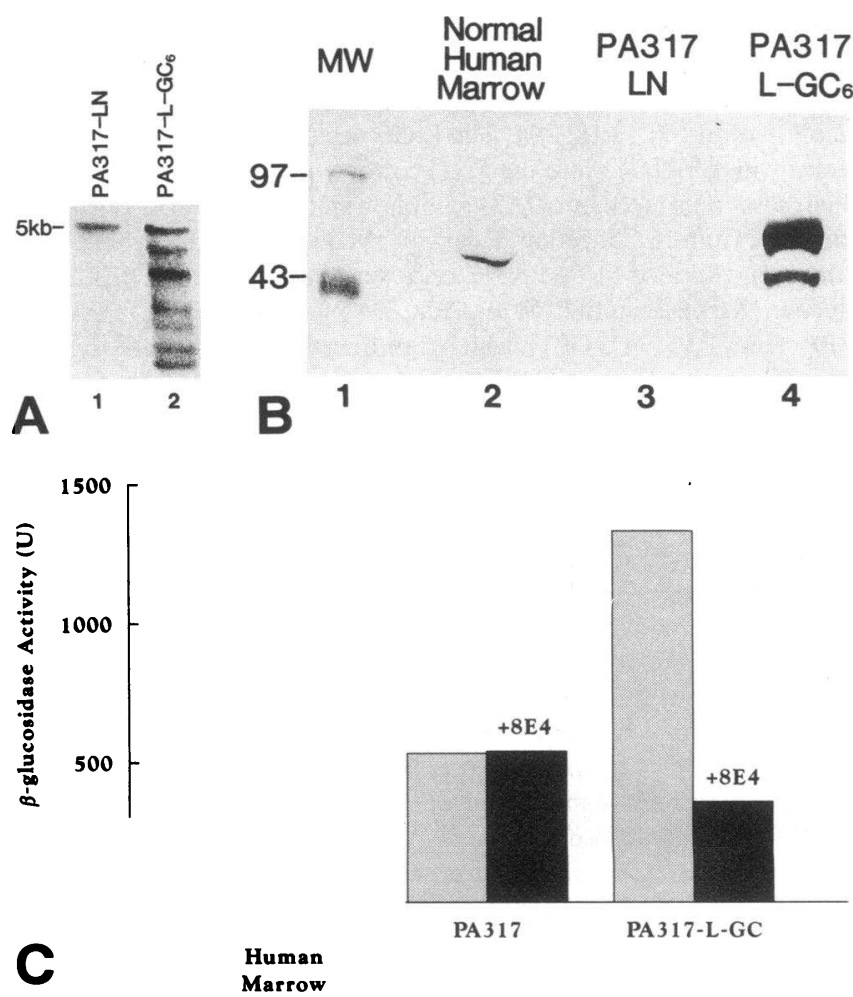

Figure 2. Characterization of an amphotropic PA317 clone producing the L-GC retroviral vector. $(A)$ Quantitation of proviral copy number by Southern blot analysis. Genomic DNA from PA317/LN (lane 1) and PA317/L-GC 6 (lane 2) cells was digested with EcoR1, resolved on a $1 \%$ agarose gel, transferred to nylon membrane, and hybridized with the human GC cDNA probe. The band at $5 \mathrm{~kb}$ represents the endogenous murine $\mathrm{GC}$ gene. The PA317/L-GC 6 clone contains an additional six bands, which represent vector proviral integrants. $(B)$ Production of vector-derived human GC detected by Western blot analysis. $30 \mu \mathrm{g}$ of total cellular protein from nonadherent cells harvested from long-term culture was electrophoresed in a $10 \%$ SDS-polyacrylamide gel, transferred to nitrocellulose, and incubated with the 8E4 monoclonal antibody, which is specific for human GC. (C) Quantitation of human GC enzymatic activity by selective immunoprecipitation. GC enzymatic activity was measured by incubation with the synthetic fluorogenic substrate 4-methyl-umbelliferyl- $\beta$ D-glucopyranoside (4-MU; Sigma Chemical Co.) followed by fluorometry. Units of GC activity are defined as nanomoles 4-MU produced per minute per milligram of protein. GC activity was measured before (solid bars) and after (shaded bars) immunoprecipitation with the monoclonal antibody 8E4 and Staphylococcus aureus protein A beads (Calbiochem-Behring Corp., La Jolla, CA).

human GC-specific antibody. The PA317/L-GC 6 cell line produced approximately threefold more GC than the parental PA317 cell line, and the increment of activity was precipitated by $8 \mathrm{E} 4$. These results demonstrate that the increased total level of GC enzyme activity in the PA317/L-GC 6 clone was due to expressed human GC. Based upon these results demonstrating the high level of functional GC produced by the PA317/L-GC clone, it was used for subsequent studies of gene transduction of the Gaucher marrow.

Comparison of gene transfer efficiency into the progenitor cells in whole-marrow versus $C D 34^{+}$cells. To measure the efficiency of gene transfer into the hematopoietic progenitor cells 
of the Gaucher marrow, we used the LN vector which carries the dominant selectable $n e o$ gene. Gene transfer efficiency was compared using either the total mononuclear cell fraction of the marrow or progenitor cells enriched by immunomagnetic selection of the $\mathrm{CD} 34^{+}$cells. Marrow cells were prestimulated with medium containing IL- 3 and IL-6 and co-cultivated on PA317 cells producing the $\mathrm{LN}$ vector. Samples of the LNtransduced marrow were plated in methylcellulose-supported colony-forming assay with or without G418.

Examination of the frequency of colony-forming cells in the absence of G418 reveals the degree of purification of progenitor cells produced by the CD34 enrichment. From $4 \times 10^{5}$ mononuclear marrow cells plated in experiments $1,3,4$, and 5 , a total of 795 colonies were formed in the absence of G418 ( $0.20 \%$ colony-forming progenitor cells, Table I). The CD34enriched marrow formed 593 colonies from 4,600 cells plated in five separate experiments (12.9\% progenitor cells). Thus, the CD34-immunomagnetic sorting procedure resulted in an $\sim 65$-fold enrichment of colony-forming cells (range 36-133fold).

Of the colonies that formed from the LN-transduced marrow, 40-45\% were resistant to G418 (Table I). In each experiment, marrow was also transduced with the vector $L$ $\mathrm{GC}$, which does not contain the neo gene. G418-resistant colonies were never seen in the L-GC-transduced marrow samples, demonstrating the stringency of the selection for neo gene transfer at the concentration of G418 that was used. Gene transfer occurred with equal frequency into progenitors within whole mononuclear or CD34-enriched populations. Overall, the LN vector transduced $43.1 \%( \pm 1.3 \mathrm{SEM}, n=4)$ of the progenitors in the unseparated marrow and $39.0 \%( \pm 2.0 \mathrm{SEM}$, $n=5)$ in the CD34-enriched population $(P=0.31)$. Thus a 65 -fold purification of the target progenitor cells did not significantly affect the percentage of cells which were transduced by the $\mathrm{LN}$ retroviral vector.

LTBMC of transduced Gaucher CD $34^{+}$bone marrow cells. For all subsequent experiments to measure expression of the transduced GC gene, we used only CD34-enriched marrow cells to initiate the LTBMC. After transduction by the LN or L-GC vector, marrow cells were maintained in LTBMC. Culture conditions were chosen to favor myeloid differentiation, including supplementation with recombinant human GM-
CSF and hydrocortisone. To characterize the cells produced by the LTBMC, cytocentrifuge preparations were made of the nonadherent cells. Morphologic analysis of the preparations using Wright/Giemsa stain consistently revealed the predominant cells to be of monocytoid or myeloid appearance. A representative sample of nonadherent cells obtained from an LTBMC of Gaucher marrow 3 mo after transduction by L-GC contained $67 \%$ monocytoid cells, $30 \%$ myeloid forms, and $3 \%$ undifferentiated blasts. Nonspecific esterase staining, a marker of the monocytic lineage, was positive in $27 \%$ of the cells. Therefore, the staining showed that the mature cells produced in the LTBMC were primarily of the myelomonocytic lineages.

Expression of GC RNA by transduced marrow maintained in LTBMC. To analyze expression by the $\mathrm{L}-\mathrm{GC}$ and $\mathrm{LN}$ vectors, nonadherent cells were collected from LTBMC for Northern blot analysis after various periods of culture. Fig. $3 A$ shows hybridization with the human GC probe of RNA harvested from LTBMC of Gaucher marrow 1 mo after transduction. Lane 1 contains RNA from an LN-transduced culture, and demonstrates the normal pattern of mature human GC mRNA expression, with a major band of $\sim 2 \mathrm{~kb}$ in size (26). Although the marrow is from a patient with Gaucher disease, the RNA transcripts are of normal size, as is typically seen (27). Lane 2 contains RNA from a culture transduced by L-GC, and shows an additional band at $3 \mathrm{~kb}$, which represents the vector GC transcript. The intensity of the vector transcript is equal to that of the endogenous GC mRNA. Expression of the inserted gene was, therefore, occurring at normal levels in the nonadherent cells from LTBMC, which were primarily myelomonocytic. Rehybridization of the same blot with the neo probe shows a complementary pattern of expression ( Fig. $3 B$ ). A vector band of $2.5 \mathrm{~kb}$ is seen in the LN-transduced marrow, while the LGC-transduced cells serve as a negative control for neo RNA.

Fig. $3 C$ shows RNA from the same LTBMC, harvested 3 and 5 mo after transduction with L-GC. Again, the blot was hybridized with the human GC probe. Expression of the vector-derived GC transcripts at levels equal to or greater than endogenous GC mRNA levels persisted. The continued production of mature hematopoietic cells expressing vector transcripts for up to 5 mo suggests that we have transduced longterm culture initiating cells (LTCIC), a primitive population of progenitor cells (28).

Table I. Total and G418-resistant Colonies from Gaucher Bone Marrow

\begin{tabular}{|c|c|c|c|c|c|c|c|c|c|}
\hline \multicolumn{10}{|c|}{ Marrow transduced with the $\mathrm{LN}$ vector } \\
\hline \multirow[b]{2}{*}{ Expt. } & \multicolumn{4}{|c|}{ Total marrow mononuclear cells } & \multicolumn{4}{|c|}{ CD34-enriched marrow cells } & \\
\hline & CFU-GM & BFU-E & CFU mix & Total & CFU-GM & BFU-E & CFU mix & Total & \\
\hline 1 & $75 / 193^{*}$ & $11 / 23$ & $15 / 33$ & $101 / 249$ & $21 / 50$ & $3 / 8$ & $5 / 12$ & $29 / 70$ & $(400)^{\ddagger}$ \\
\hline 2 & - & - & - & - & $39 / 84$ & $4 / 11$ & $5 / 10$ & $48 / 105$ & $(400)$ \\
\hline 3 & $74 / 170$ & $6 / 10$ & $6 / 15$ & $86 / 195$ & $64 / 169$ & $8 / 17$ & $11 / 30$ & $83 / 216$ & $(800)$ \\
\hline 4 & $69 / 137$ & $1 / 9$ & $4 / 13$ & $74 / 159$ & $21 / 52$ & $1 / 4$ & $2 / 6$ & $24 / 62$ & $(1,000)$ \\
\hline 5 & - $67 / 159$ & $7 / 14$ & $8 / 19$ & $82 / 192$ & $39 / 109$ & $1 / 12$ & $7 / 19$ & $47 / 140$ & $(2,000)$ \\
\hline$\Sigma$ & $285 / 659$ & $25 / 56$ & $33 / 80$ & $343 / 795$ & $184 / 464$ & $17 / 52$ & $30 / 77$ & $231 / 593$ & \\
\hline $\begin{array}{l}\text { Percentage of G418- } \\
\text { resistant colonies }\end{array}$ & 43.2 & 44.6 . & 41.3 & 43.1 & 39.7 & 32.7 & 40.0 & 39.0 & \\
\hline
\end{tabular}

* Colonies formed in the presence of $1.0 \mathrm{mg} / \mathrm{ml}$ active G418/colonies formed in the absence of G418. For total mononuclear marrow cells, two plates each with $5 \times 10^{4}$ cells were plated for each point. ${ }^{\ddagger}$ For CD34-enriched marrow, the numbers of cells plated for each point are indicated in parentheses. 
A
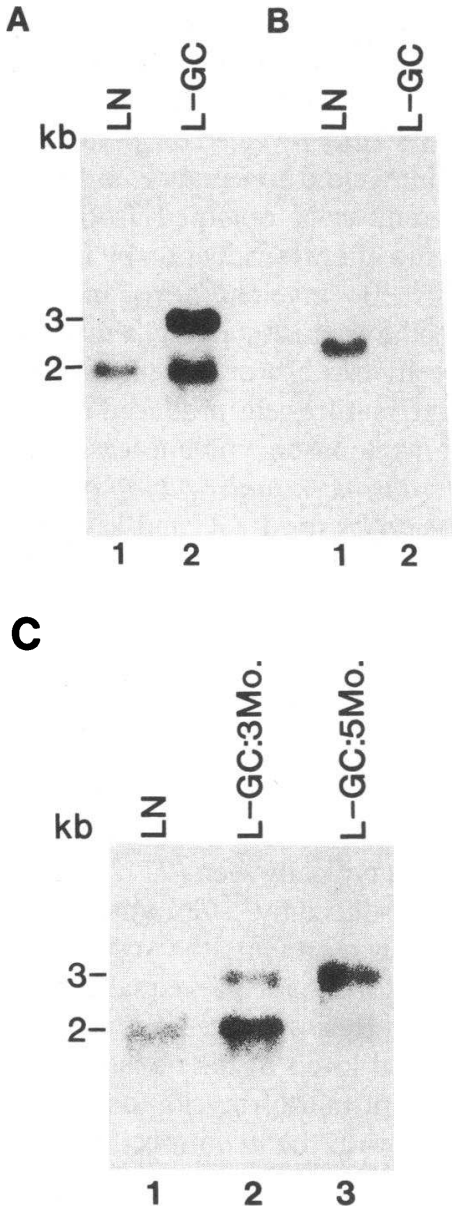

Figure 3. Northern blot analysis of vector-derived GC expression in cells from LTBMC. Nonadherent cells were collected from LTBMC initiated with transduced Gaucher marrow. Total cellular RNA was prepared by guanidinium isothiocyanate/acid phenol extraction, resolved on a $1.2 \%$ agarose-formaldehyde gel, and transferred to nylon membrane. $(A)$ Cells were harvested 1 mo post-transduction. The blot was hybridized with the human GC cDNA probe. RNA from a LTBMC of Gaucher marrow which had been transduced by the control LN vector (lane 1) shows a hybridization band of $\sim 2 \mathrm{~kb}$ in size, which represents the endogenous GC mRNA. Gaucher marrow transduced by the LGC vector (lane 2 ) contains an additional hybridizing band of $3 \mathrm{~kb}$, which represents the vector-derived $\mathrm{GC}$ transcript. (B) The blot from $A$ was rehybridized with the neo probe. The LN-transduced marrow (lane 1) has a band of $2.5 \mathrm{~kb}$, which represents neo mRNA. RNA from the L-GC transduced LTBMC has no neo expression. $(C)$ Cells were harvested from LTBMC 3 mo (lanes $l$ and 2) and 5 mo (lane 3) after transduction with the LN or L-GC vectors. The endogenous GC mRNA is seen in each sample and acts as a control for the amount of RNA loaded in each lane. The 3-kb band represents vector-derived GC transcripts.

Western blot analysis of GC levels in L-GC transduced Gaucher marrow. Western blot analysis was done to assess the levels of GC protein produced in nonadherent cells from transduced Gaucher cells from LTBMC. Fig. 4 shows protein from samples harvested from LTBMC 1 mo post-transduction. Lane 2 contains protein from a culture initiated with normal human marrow. An immunoreactive GC protein band of $55-65 \mathrm{kD}$ is detected by the monoclonal antibody $8 \mathrm{E} 4$. Lane 3 contains protein from an LTBMC initiated with Gaucher marrow after

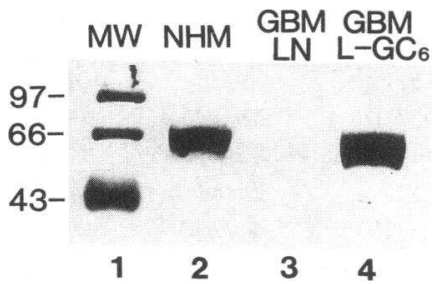

Figure 4. Quantitation of immunoreactive GC protein produced in LTBMC. Nonadherent cells were harvested from LTBMC 1 mo post-transduction and analyzed by Western blot analysis as described (Fig. $2 B$ legend). Cells collected from the LTBMC initiated

with Gaucher bone marrow ( $G B M)$ transduced by the $L N$ vector (lane 3 ) contains no immunoreactive GC protein. Cells from the LTBMC initiated with Gaucher bone marrow transduced by the LGC vector (lane 4) contained approximately the same amount of protein as cells from normal human marrow (NHM, lane 2).

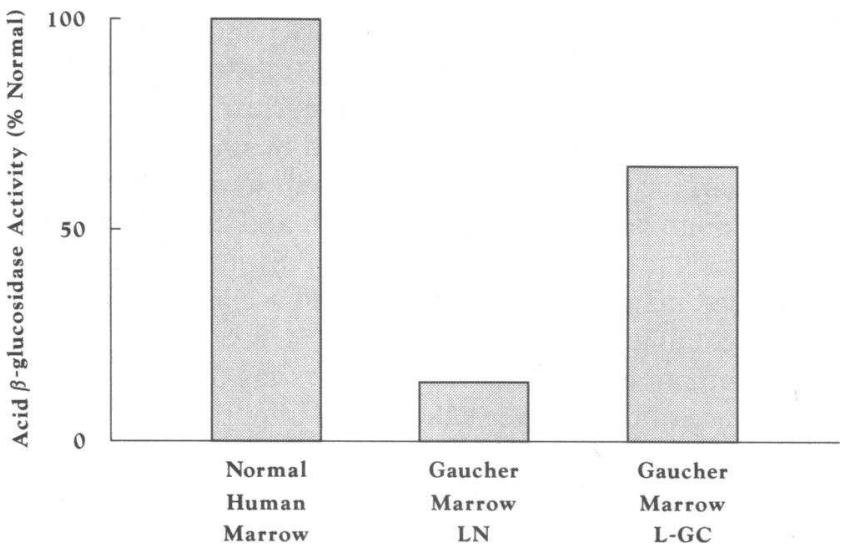

Figure 5. GC enzymatic activity in LTBMC. Nonadherent cells were collected from three separate LTBMC 1 mo after transduction. GC enzyme activity was quantitated as described (Fig. $2 C$ legend).

transduction with the control $\mathrm{LN}$ vector. These cells contain very little immunoreactive protein, as has been previously reported for cells from patients with type 3 Gaucher disease (29). Lane 4 contains protein from nonadherent marrow cells harvested from LTBMC of the Gaucher marrow after transduction with L-GC. The L-GC transduced marrow shows levels of immunoreactive GC equal to that produced by the normal marrow cells.

Enzymatically active GC production in L-GC transduced Gaucher bone marrow. In three separate experiments, enzymatic activity was measured on the nonadherent cells from LTBMC of normal and Gaucher marrow 1 mo after gene transfer (Fig. 5). The LN-transduced Gaucher marrow had only $16.9 \%( \pm 3.3$, SEM $)$ of normal GC activity, which is in the range that has previously been observed for cells from patients with type 3 Gaucher disease (29). After transduction by the L-GC vector, the Gaucher marrow contained increased levels of enzymatic activity ( $58.1 \% \pm 11.0$ of normal).

\section{Discussion}

Our results demonstrate high-efficiency transfer and persistent expression of the human GC gene by the L-GC retroviral vector in bone marrow cells from a patient with type 3 Gaucher disease. Expression of GC in the myelomonocytic cells produced by the transduced marrow maintained in LTBMC was confirmed at the levels of both RNA (by Northern blot analysis) and protein (by Western blot analysis and GC enzyme assay). The continued expression of GC for 5 mo in LTBMC demonstrates that stable transduction of long-lived human hematopoietic progenitor cells has been achieved. These LTCIC have been postulated to be closely related to the pluripotent hematopoietic stem cells that produce hematologic reconstitution after BMT (28) and would be the specific target for gene transfer for human gene therapy.

To optimize the extent of retroviral-mediated gene transfer into LTCIC, we precultured the marrow with medium containing IL-3 and IL- 6 before co-cultivation with the vector-producing cells. We and others have found that this combination of growth factors causes an increase in the number of cycling progenitor cells and a corresponding increase in the level of gene transfer by retroviral vectors $(17,30,31)$. 
We directly compared the gene transfer efficiency using either the total marrow mononuclear cell fraction or a population enriched for progenitor cells by immunomagnetic isolation of $\mathrm{CD}_{34}{ }^{+}$cells. The $\mathrm{CD} 34^{+}$fraction of human marrow has been demonstrated to produce hematologic reconstitution after autologous BMT and therefore contains true pluripotent hematopoietic stem cells (32). Equal extents of gene transfer into the progenitor cells of each population were achieved, despite an $\sim 65$-fold enrichment for the target progenitor cells in the $\mathrm{CD} 34^{+}$fraction. The ability to use purified cell preparations for clinical gene therapy will simplify the logistics of handling the large numbers of cells needed for autologous BMT. As further advances are made into identification of the characteristics of human hematopoietic stem cells, it may be possible to further purify the target cells.

The gene transfer efficiency we obtained using the progenitor cells in marrow from the Gaucher patient $(40-45 \%)$ was similar to levels we have previously reported with marrow from normal donors, when using the same protocol (17). Therefore, the presence of numerous Gaucher macrophages in the marrow did not appear to affect the process of retroviral vector transduction. These results imply that retroviral-mediated gene transduction of Gaucher marrow is technically feasible for clinical gene therapy.

The persistent expression of vector-derived GC in progeny of the transduced cells in LTBMC for 5 mo demonstrates that marrow from patients with Gaucher disease can be effectively and stably transduced by retroviral vectors. After transduction with the L-GC vector, which carries the normal GC cDNA, marrow from a Gaucher patient produced $\sim 60 \%$ of normal GC levels. GC expression at this level should be of clinical benefit, in that heterozygous Gaucher carriers expressing 50\% of normal GC levels are asymptomatic (33).

The nonadherent cells from long-term culture which were analyzed for GC expression were primarily mature myelomonocytic, as shown by Wright/Giemsa and nonspecific esterase staining. We observed sustained expression of GC RNA from the L-GC vector in these cells for as long as $5 \mathrm{mo}$, which was the duration of LTBMC. The expression of vector-derived GC in mature monocytoid cells is significant because they are the specific mature cell type that must be corrected for gene therapy of Gaucher disease.

Our studies represent a significant advance over the prior report of Fink et al. (16), because we have achieved normal levels of GC expression in marrow from a Gaucher patient without the need to select for transduced cells with G418. The ability to efficiently transduce progenitor cells without a requirement for drug selection will be important for clinical applications, inasmuch as $\mathrm{G} 418$ has been shown to reduce the ability of marrow to reconstitute mice $(34,35)$, and may similarly compromise human marrow. The greater gene transfer frequency that we achieved is likely due to the use of recombinant human growth factors to stimulate progenitor cell proliferation. A recent report has demonstrated a similar high rate of gene transfer into progenitor cells from patients with adenosine deaminase deficiency after preculture of the marrow with IL-3 and IL-6 (36).

Although we demonstrate gene transfer with sustained expression into LTCIC, it is not possible to demonstrate that true pluripotent human stem cells have been transduced, using in vitro systems. Stem cells can only be identified by their produc- tion of sustained multilineage reconstitution after BMT. An experimental system is needed which will confirm transduction of true human stem cells, as well as long-lived committed progenitor cells. Immunodeficient mice may provide a useful model for analysis of pluripotent human stem cell activity (3739). Demonstration of sustained long-term expression of genes transferred into hematopoietic stem cells by retroviral vectors in a large animal model may also provide additional confirmation of stem cell transduction and provide the basis for clinical trials of gene therapy for genetic disease by bone marrow transplantation.

\section{Acknowledgments}

We thank A.T. and her parents for their cooperation in providing the bone marrow samples used for these studies. Dr. Gay Crooks performed staining and differential counts of LTBMC cells. Drs. Robert Overell and Douglas Williams at Immunex Corp., Seattle, WA, generously provided recombinant human hematopoietic growth factors. Dr. Curt Civin, Johns Hopkins Medical School, Baltimore, MD, provided the My10 monoclonal antibody.

These studies were supported by a March of Dimes Basil O'Connor Starter Scholar Award (No. 5-735) and by a research award from the National Institute of Diabetes and Digestive and Kidney Diseases (R01-DK42694).

\section{References}

1. Beutler, E. 1991. Gaucher's disease. N. Engl. J. Med. 325:1354-1360.

2. Grabowski, G. A., S. Gatt, and M. Horowitz. 1990. Acid beta-glucosidase: enzymology and molecular biology of Gaucher disease. Crit. Rev. Biochem. Mol. Biol. 25:385-414.

3. Rappeport, J. M., J. A. Barranger, and E. I. Ginns. 1986. Bone marrow transplantation in Gaucher disease. Birth Defects. 22:101-109.

4. Ringdon, O., C. G. Groth, A. Erikson, L. Backman, S. Granqvist, J. E. Mansson, and L. Svennerholm. 1986. Long-term follow-up of the first successful bone marrow transplantation in Gaucher disease. Transplantation (Baltimore). 46:66-70.

5. Hobbs, J. R., K. H. Jones, P. J. Shaw, L. Lindsay, and M. Hancock. 1987. Beneficial effect of pre-transplant splenectomy on displacement bone marrow transplantation for Gaucher's syndrome. Lancet. $i: 1111-1115$.

6. Parkman, R. 1986. The application of bone marrow transplantation to the treatment of genetic diseases. Science (Wash. DC). 232:1373-1378.

7. Tsuji, S., P. V. Choudary, B. M. Martin, S. Winnfield, J. A. Barranger, and E. I. Ginns. 1986. Nucleotide sequence of cDNA containing the complete coding sequence for human lysosomal glucocerebrosidase. J. Biol. Chem. 261:50-53.

8. Sorge, J., C. West, B. Westwood, and E. Beutler. 1985. Molecular cloning and nucleotide sequence of the human glucocerebrosidase cDNA. Proc. Natl. Acad. Sci. USA. 82:7289-7293. With correction, 83:3567, 1986.

9. Karlsson, S. 1991. Treatment of genetic defects in hematopoietic cell function by gene transfer. Blood. 78:2481-2492.

10. Williams, D. A. 1990. Expression of introduced genetic sequences in hematopoietic cells following retroviral-mediated gene transfer. Hum. Gene Ther. 1:229-239.

11. Nolta, J. A., L. S. Sender, J. A. Barranger, and D. B. Kohn. 1990. Expression of human glucocerebrosidase in murine long-term bone marrow cultures following retroviral vector-mediated gene transfer. Blood. 75:787-797.

12. Correll, P. H., Y. Kew, L. K. Perry, R. O. Brady, J. K. Fink, and S. Karlsson. 1990. Expression of human glucocerebrosidase in long-term reconstituted mice following retroviral-mediated gene transfer into hematopoietic stem cells. Hum. Gene Ther. 1:277-287.

13. Weinthal, J., J. A. Nolta, X. J. Yu, J. Lilley, L. Uribe, and D. B. Kohn. 1991. Expression of human glucocerebrosidase following retroviral vector-mediated transduction of murine hematopoietic stem cells. Bone Marrow Transplant. 8:403-412.

14. Choudary, P. V., J. A. Barranger, S. Tsuji, J. Mayor, M. E. LaMarca, C. L. Cepko, R. C. Mulligan and E. I. Ginns. 1986. Retrovirus-mediated transfer of the human glucocerebrosidase gene to Gaucher fibroblasts. Mol. Biol. Med. 3:293299.

15. Sorge, J., W. Kuhl, C. West, and E. Beutler. 1987. Complete correction of the enzymatic defect of type I Gaucher disease fibroblasts by retrovirus-mediated gene transfer. Proc. Natl. Acad. Sci. USA. 84:906-909. 
16. Fink, J. K., P. H. Correll, L. K. Perry, R. O. Brady, and S. Karlsson. 1990. Correction of glucocerebrosidase deficiency after retroviral-mediated gene transfer into hematopoietic progenitor cells from patients with Gaucher disease. Proc. Natl. Acad. Sci. USA. 87:2334-2338.

17. Nolta, J. A., and D. B. Kohn. 1990. Comparison of the effects of growth factors on retroviral vector-mediated gene transfer and the proliferative status of human progenitor cells. Hum. Gene Ther. 1:257-268.

18. Miller, A. D., and G. J. Rosman. 1989. Improved retroviral vectors for gene transfer and expression. Biotechniques. 7:980-990.

19. Miller, A. D., and C. Buttimore. 1986. Redesign of retrovirus packaging cell lines to avoid recombination leading to helper virus production. Mol. Cell. Biol. 6:2895-2902.

20. Kohn, D. B., J. A. Nolta, C. M. Hong, and J. A. Barranger. 1989. Expression of the human glucocerebrosidase gene using retroviral vectors. In Gene Transfer and Gene Therapy. UCLA (Univ. Calif. Los Angeles) Symp. Mol. Cell. Biol. New Ser. 87:397-408.

21. Mann, R., R. C. Mulligan, and D. Baltimore. 1983. Construction of a retrovirus packaging mutant and its use to produce helper-free defective retrovirus. Cell. 33:153-159.

22. Morgan, R. A., K. Cornetta, and W. F. Anderson. 1990. Applications of the polymerase chain reaction in retroviral mediated gene transfer and the analysis of gene marked human TIL cells. Hum. Gene Ther. 1:257-268.

23. Strauss, L. C., T. M. Trischmann, S. D. Rowley, J. M. Wiley, and C. I. Civin. 1991. Selection of normal human hematopoietic stem cells for bone marrow transplantation using immunomagnetic microspheres and CD34 antibody. Am. J. Pediatr. Hematol. Oncol. 13:217-221.

24. Chomczynski, P., and W. Sacchi. 1987. Single-step method of RNA isolation by acid guanidinium thiocyanate-phenol-chloroform extraction. Anal. Bio chem. 162:156-159.

25. Aerts, M. F. G., W. E. Donker-Koopman, M. K. Van Der Vliet, L. M. V. Jonsson, E. I. Ginns, G. J. Murray, J. A. Barranger, J. M. Tager, and A. W. Shram. 1985. The occurrence of two immunologically distinguishable $\beta$-glucocerebrosidases in human spleen. Eur. J. Biochem. 150:565-574.

26. Reiner, O., M. Wigderson, and M. Horowitz. 1988. Structural analysis of the human glucocerebrosidase genes. DNA (NY). 7:107-116.

27. Graves, P. N., G. A. Grabowski, M. D. Ludman, P. Palese, and F. I. Smith 1986. Human acid $\beta$-glucosidase: Northern blot and S1 nuclease analysis of mRNA from HeLa cells and Normal and Gaucher disease fibroblasts. Am. J. Hum. Genet. 39:763-774.

28. Sutherland, H. J., C. J. Eaves, A. C. Eaves, W. Dragowska, and P. M.
Lansdorp. 1989. Characterization and partial purification of human marrow cells capable of initiating long-term hematopoiesis in vitro. Blood. 74:1563-1570.

29. Fabbro, D., R. S. Desnick, and G. A. Grabowski. 1987. Gaucher disease: genetic heterogeneity within and among the subtypes detected by immunoelectroblotting. Am. J. Hum. Genet. 40:15-31.

30. Bodine, D. M., S. Karlsson, and A. W. Nienhuis. 1986. Combination of interleukins 3 and 6 preserves stem cell function in culture and enhances retrovirus-mediated gene transfer into hematopoietic stem cells. Proc. Natl. Acad. Sci. USA. 86:8897-8901.

31. Suda, T., J. Suda, and M. Ogawa. 1983. Proliferation kinetics and differentiation of murine blast cell colonies in culture: evidence for variable $G_{0}$ periods and constant doubling rates of early pluripotent hematopoietic progenitors. $J$ Cell. Physiol. 117:308-318.

32. Berenson, R. J., W. I. Bensinger, R. S. Hill, R. G. Andrews, J. Garcia-Lopez, D. F. Kalamasz, B. J. Still, G. Spitzer, C. D. Buckner, and I. D. Bernstein 1991. Engraftment after infusion of $\mathrm{CD} 34^{+}$marrow cells in patients with breast cancer or neuroblastoma. Blood. 77:1717-1722.

33. Beutler, E., W. Kuhl, F. Trinidad, R. Teplitz, and H. Nadler. 1971. $\beta$-Glucosidase activity in fibroblasts from homozygotes and heterozygotes for Gaucher's disease. Am. J. Hum. Genet. 23:62-66.

34. Bender, M. A., R. E. Gelinas, and A. D. Miller. 1989. A majority of mice show long-term expression of a human $\beta$-globin gene after retroviral transfer into hematopoietic stem cells. Mol. Cell. Biol. 9:1426-1434.

35. Karlsson, S., D. M. Bodine, L. Perry, T. Papayannopoulou, and A. W. Neinhuis. 1988. Expression of the human $\beta$-globin gene following retroviral-mediated transfer into multipotential hematopoietic progenitors of mice. Proc. Natl. Acad. Sci. USA. 85:6062-6066.

36. Cournoyer, D., M. Scarpa, K. Mitani, K. A. Moore, D. Markowitz, A. Bank, J. W. Belmont, and C. T. Caskey. 1991. Gene transfer of adenosine deaminase into primitive human hematopoietic progenitor cells. Hum. Gene Ther. 2:203-213.

37. McCune, J. M., R. Namikawa, H. Kaneshima, L. D. Shultz, M. Lieberman, and I. L. Weissman. 1988. The SCID-hu mouse: murine model for the analysis of human hematolymphoid differentiation and function. Science (Wash. DC). 241:1632-1639.

38. Dick, J. E., S. Kamel-Reid, B. Murdoch, and M. Doedens. 1991. Gene transfer into normal human hematopoietic cells using in vitro and in vivo assays. Blood. 78:624-634.

39. Dick, J. E., T. Lapidot, and F. Pflumio. 1991. Transplantation of normal and leukemic human bone marrow into immune-deficient mice: Development of animal models for human hematopoiesis. Immunol. Rev. 124:25-43. 